\title{
CIDADE DE DEUS: DICÇÃO NEGRO-PERIFÉRICA EM FORMA DE ROMANCE
}

\author{
Thiago Martins Rodrigues \\ Licenciando em Letras pela Universidade Federal do Rio Grande do Sul (UFRGS). \\ Bolsista CNPq. \\ thiago-rodrigues27@hotmail.com \\ Antônio Marcos Vieira Sanseverino \\ Professor Associado de Literatura Brasileira da Universidade Federal do Rio Grande do Sul \\ (UFRGS). Pesquisador CNPq. \\ amvsanseverino@gmail.com
}

\section{RESUMO}

O presente trabalho pretende analisar o romance Cidade de Deus (1997), de Paulo Lins, observando como o autor estrutura em forma de romance a violência e o racismo denunciados pela dicção negra da literatura brasileira. A partir de Formação da Literatura Brasileira (1962), questionase que lugar tem a narrativa negra (CUTI, 2010) nesta linha sucessória de obras, considerando sua recepção. Conclui-se que há uma segunda formação da literatura brasileira não expressa por Candido, que é negra, e que a crítica literária branca não dá conta de analisá-la e interpretá-la em profundidade, levando em consideração as questões étnicoraciais que provocam mudanças significativas no modo de organização das narrativas.

Palavras-chave: Cidade de Deus; Literatura Negro-brasileira; Romance.

\section{RESUMEN}

El presente trabajo pretende analizar la novela Cidade de Deus (1997), de Paulo Lins, observando como el autor organiza en forma de novela la violencia y el racismo denunciados por la dicción negra de la literatura brasileña. A partir de Formação da Literatura Brasileira (1962) se pregunta qué lugar ocupa la narrativa negra (CUTI, 2010) en esta línea sucesoria de obras, considerando su recepción. Se concluye que hay una segunda formación de la literatura brasileña no expresa por Candido, que es negra, y que la crítica literaria blanca no consigue analizarla e interpretarla con profundidad, considerando las cuestiones étnicoraciales que provocan cambios significativos en el modo de organización de las narrativas.

Palabras clave: Cidade de Deus; Literatura Afro brasileña; Novela. 
É preciso que se olhe para Cidade de Deus entendendo seu lugar - ou não-lugar dentro do sistema literário brasileiro. ${ }^{1}$ Para tanto, lemos o romance observando a articulação inextricável entre forma estética e matéria negra. Há um jogo de concessões mútuas entre elas, já que aquela implica em ajustes nesta e vice-versa. A matéria da violência, do tráfico crescente, do crime e da exclusão racial estabelece certo modo de narrar. A narrativa da trajetória do complexo habitacional Cidade de Deus foi tecida por Paulo Lins a partir um determinado princípio estético, que tentaremos recuperar. $\mathrm{O}$ autor utiliza a forma do romance, fazendo com que suas estruturas tradicionalmente preestabelecidas se façam presentes na obra. Buscamos esboçar, minimamente, um lugar para o romance, justificando-o como uma espécie de marco de um modo de representação da violência e da exclusão brasileira na literatura contemporânea de autoria negro-periférica.

Cidade de Deus é lançado em 1997 com grande alvoroço. A mídia repercutiu amplamente o empreendimento de Paulo Lins, à época um estreante em textos em prosa. O autor, que viveu no complexo habitacional desde os seis anos de idade até a vida adulta, colheu material para sua obra não só como morador, mas também como pesquisador. Lins é graduado em Letras e participou do grupo de pesquisas da antropóloga Alba Zaluar, entre 1986 e 1993, que realizou um trabalho de campo na Cidade de Deus, tentando mapear a violência no lugar. Analisando a influência da pesquisa no romance, Costa (2008) recupera o contexto em que o conjunto habitacional foi construído: 
favelas da época - "Cidade de Deus" realmente parecia ser um lugar divino. No entanto, como nem tudo é o que parece, a falta de manutenção e de organização, acabou por transformar o conjunto em mais uma favela. (COSTA, 2008, p. 31)

Na mesma reflexão, aponta-se também a importância da inserção do autor na atividade etnográfica:

Paulo Lins vivia na favela carioca nos anos 80, quando Alba Zaluar conduziu a pesquisa antropológica "Crime e Criminalidade nas Classes Populares". Foi escolhido para ser um de seus colaboradores porque cursava o ensino superior e conhecia bem a favela. Essa experiência foi fundamental para a construção do romance. Nos oito anos em que participou da pesquisa, Lins colheu material, participou de discussões e, mais do que qualquer outra coisa, ouviu muitas conversas. A condensação desse material o levava a escrever - mas não os relatórios "científicos" que supostamente se apresentariam nesse tipo de pesquisa acadêmica. (COSTA, 2008, p. 33)

Desta forma, não é incomum que seja atribuída à obra a alcunha de romance etnográfico, o que não nos parece reduzir seu valor, uma vez que o autor consegue, de fato, reconstituir a perspectiva negra da exclusão e da violência, segundo defendemos aqui. A proximidade com a pesquisa de campo fez com que, em uma primeira versão, fossem utilizados nomes e apelidos reais para as personagens. Posteriormente, os nomes precisaram ser trocados para preservar a identidade dos sujeitos.

A euforia foi tanta que a história do conjunto habitacional chegou ao cinema. É latente que o meio intelectual em que Lins estava inserido fez com que seu romance fosse recebido de maneira distinta a que a crítica literária costuma receber obras de autoria negra. Todas as produções literárias negras sempre tiveram de contar com a crítica literária branca. Nesse sentido, acompanhamos aqui a reflexão de Cuti (2010):

O branco, como recepção do texto de um negro, historicamente foi hostil. Vencer essa hostilidade lastreada na postura de quem não se dispõe a dividir o poder com alguém que, por quatro séculos, teve o mínimo de poder é a grande aventura do escritor negro que se quer negro em sua escrita. Entretanto, 
acomodar-se a essa hostilidade pode ser uma estratégia ou uma renúncia. (CUTI, 2010, p. 51)

Uma das críticas mais entusiásticas foi feita por Roberto Schwarz em seu ensaio "Uma aventura artística incomum", publicado no jornal Folha de S. Paulo, em 7 de setembro de 1997, e, posteriormente, na compilação de ensaios Sequências Brasileiras $(1999)^{2}$. Schwarz classifica o livro como uma "aventura estética fora do comum" (SCHWARZ, 1999, p. 163). Na leitura do crítico, Cidade de Deus faz emergir uma voz negra representativa e crítica sobre o processo histórico de exclusão, que culmina nas favelas brasileiras. Parte da reflexão que propomos está alicerçada na perspectiva schwarzeana. Recuperamos aqui, a partir do ensaio, alguns modelos de referência para a obra de Paulo Lins. Não é preciso que nos esforcemos para reconhecer uma fermentação naturalista no romance. A aproximação da ficção com as vinhetas narrativas levantadas pelo trabalho de campo no conjunto habitacional deixam entrever o arquétipo de análise social presente em $O$ cortiço (1890), de Aluísio Azevedo, que se alimentou do romance experimental de Émile Zola, que sugeria ao romancista primeiro pesquisar seu objeto de estudos, tomar profusamente notas do ambiente, descrever seus principais aspectos, anotar aspectos marcantes, para, então, inserir a personagem no meio, como uma experiência, a ciência levada à literatura. Algo que ecoa na pesquisa em Cidade de Deus, que surge de uma pesquisa etnográfica, mas, vale ressaltar, que, mudada a antropologia, transforma-se também seu nexo com o romance.

Para além do princípio naturalista que subjaz a narrativa, é possível reconhecer uma ambiência análoga entre a estalagem de João Romão e o conjunto habitacional carioca do século XX, guardadas as proporções da distância temporal. Ambos os espaços são vivificados nas obras, configurando-se como esmagadores de heroísmos. Seus 
moradores estão todos expostos a uma condição de extrema exclusão, exploração e racismo, que condicionam suas ações, seus modos de vida e quaisquer expectativas futuras. A partir disso, as histórias se entrelaçam em trajetórias decadentes. No caso de Cidade de Deus, toda figura que desponte como protagonista permanece neste posto até a primeira rajada de tiros encontrar seu corpo. Lá se foram vários bicho-solto que tentaram domesticar a fúria da Cidade de Deus. Nesse sentido, o conjunto habitacional assume o protagonismo, assim como a estalagem no romance do século XIX.

Outra envergadura do romance se dá pela proximidade de Paulo Lins com o cinema. O autor participou da construção do roteiro para o filme de Fernando Meirelles e Kátia Lund, em 2002, e assinou os episódios da série também homônima para a Rede Globo. Em 2004, escreveu o roteiro do filme Quase dois irmãos. A verve cinematográfica de Lins dá as caras nas cenas descritivas, em que consegue criar planos de ações concomitantes, através da linguagem. Criminosos e policiais em perseguição são narrados lado a lado em suas movimentações até o encontro fatal com a bala. Vale questionar aqui se Cidade de Deus é um romance roteirizado ou se a matéria que expressa é que carrega a potência cinematográfica. Observamos a segunda opção como a mais produtiva, haja vista a quantidade de produções que adotam a temática da violência. Parece evidente que a violência e a exclusão brasileiras são, de fato, matérias roteirizáveis, muito em razão do interesse da indústria cultural em tornar a violência e o racismo em um fetiche, que apenas espetaculariza e recalca, diluindo as possibilidades de resistência. Essa premissa está alicerçada nas reflexões de Adorno e Horkheimer (2006 [1985]) sobre a Indústria Cultural:

O mundo inteiro é forçado a passar pelo filtro da indústria cultural. A velha experiência do espectador de cinema, que percebe a rua como um 
prolongamento do filme que acabou de ver, porque este pretende ele próprio reproduzir rigorosamente o mundo da percepção cotidiana, tornou-se a norma da produção. Quanto maior a perfeição com que suas técnicas duplicam os objetos empíricos, mais fácil se torna hoje obter a ilusão de que o mundo exterior é o prolongamento sem ruptura do mundo que se descobre no filme. (ADORNO; HORKHEIMER, 2006 [1985], p. 104)

A partir disso, entendemos que nas obras atravessadas pela indústria cultural nenhuma dimensão escapa ao seu domínio e permite ao espectador do cinema experienciar a produção de forma distinta àquilo que foi previamente estabelecido. 0 gesto interpretativo está dado a priori. Trazendo a reflexão dos frankfurtianos para a análise do romance aqui, recai sobre Cidade de Deus a latência da indústria cultural, incorporada, segundo nos parece, muito mais por sua recepção, que "adestra", para usar o termo de Adorno e Horkheimer, o leitor para uma leitura limitada aos caminhos de violência, sem perceber as possibilidades de entrada na constituição do racismo e da exclusão nas favelas cariocas.

Voltando a Roberto Schwarz, o crítico faz uma síntese dos modelos que interagem em Cidade de Deus: "Diante da tarefa de romancear a sua vasta matéria, o escritor lança mão de apoios de toda sorte, que vão de Crime e Castigo e Angústia às superproduções do cinema" (SCHWARZ, 1999, p. 163). Interessa-nos questionar por que a análise schwarzeana não aponta para referências a obras de autoria e temática negro-periféricas. A hipótese que formulamos para tal pergunta é a de que os modelos estéticos de Paulo Lins não são negros porque a Literatura Negro-brasileira não tem um sistema literário livresco consolidado, nos termos propostos por Antonio Candido (2013), que tampouco chegam às carreiras de Letras, como a feita pelo autor. Para Candido, a literatura constitui-se como: 
um sistema de obras ligadas por denominadores comuns, que permitem reconhecer as notas dominantes duma fase. Estes denominadores são, além das características internas (língua, temas, imagens), certos elementos de natureza social e psíquica [...]. (CANDIDO, 2013, p. 25)

Em Formação da literatura brasileira: momentos decisivos, o sociólogo e crítico literário enuncia as três condições para que um sistema se forme: um grupo de produtores conscientes, um público leitor e um estilo comum a ser transmitido de forma contínua (CANDIDO, 2013).

Partindo-se destes três fatores, é possível afirmar que o sistema literário livresco negro-brasileiro ainda não concluiu sua formação. As produções de autoria negra na literatura brasileira estão dispersas ao longo do tempo, sem que se forme uma continuidade literária reconhecida pela crítica. Machado de Assis já é reconhecido como um dos precursores dessa literatura. Maria Firmina dos Reis, por sua vez, está sendo revisitada com seu Úrsula, bem como Luiz Gama, com Trovas burlescas, os três no século XIX. Na transição para o XX, Lima Barreto narrou o processo da exclusão social e do racismo durante a modernização conservadora no Rio de Janeiro. Nos anos 1960, temos o acontecimento que foi Carolina Maria de Jesus, com sua obra marcante e a partir dos anos 1980 a publicação dos Cadernos Negros. Após Cidade de Deus, movimentos como o da Literatura Marginal-Periférica deram conta da produção negra. Mais recentemente, em um movimento coletivo de recuperação e de afirmação das vozes negras, chegaram ao conhecimento do público e das editoras diversos nomes, principalmente de mulheres negras, como Conceição Evaristo e Ana Maria Gonçalves.

De fato, há uma segunda formação da literatura brasileira para ser desbravada. Observamos o discurso da democracia racial como um dos fatores que atravancam o reconhecimento da produção literária negro-brasileira. A consciência crítica que emerge 
desta literatura ataca diretamente o princípio da democracia racial, explicitando que o país está alicerçado sob o paradigma racista. Acompanhando a reflexão de Silvio Almeida (2018), observamos a literatura negro-brasileira com a potência de desnaturalizar as conformações impostas pelo racismo:

O racismo, mais uma vez, permite a conformação das almas, mesmo as mais nobres da sociedade, à extrema violência a que populações inteiras são submetidas, que se naturalize a morte de crianças por "balas perdidas", que se conviva com áreas inteiras sem saneamento básico, sem sistema educacional ou de saúde, que se exterminem milhares de jovens negros por ano no que vem sendo denunciado há anos pelo movimento negro como genocídio. (ALMEIDA, 2018, p. 94)

Paulo Lins lida, portanto, com um sistema literário que não articula e apaga as referências que dialogam com sua matéria. Ainda assim, Cidade de Deus carrega certo ímpeto de validação dentro da literatura brasileira. Recorremos agora, para sustentar tal argumento, à professora Regina Dalcastagnè (2007), que faz uma interessante leitura, reconhecendo o campo literário brasileiro também como meio de exclusão:

[...] a definição dominante de literatura circunscreve um espaço privilegiado de expressão, que corresponde aos modos de manifestação de alguns grupos, não de outros. O campo literário reforça esta situação, através de suas formas de consagração e de seus aparatos de leitura crítica e interpretação. (DALCASTAGNÈ, 2007, p. 21)

O autor estruturou a obra a partir de uma "ambiguidade de estilo" (DALCASTAGNÈ, 2007, p. 26) bastante produtiva do ponto de vista estético. A forma escolhida, o romance, é um gênero híbrido, que incorpora diversos discursos. Ainda que tenha sido consagrado pela lógica burguesa europeia, distante da matéria que Cidade de Deus expressa, mas que se torna capaz de abarcar uma antítese a esta formulação justamente pelo movimento de ampliação para uma dimensão coletiva, visto no século 
XIX em autores como Zola e Balzac. Em um primeiro momento, seria compreensível afirmar-se que forma estética e matéria negra são incompatíveis aqui. A história do conjunto habitacional não recai sobre um único ponto de vista, não narra a vida de um herói. Estão postos ali diversos microuniversos que compõem um todo organizado pela violência e pela exclusão.

Em Cidade de Deus, o princípio que organiza a narrativa é o da coletividade, não o da unidade, o que à primeira vista se esperaria de um romance. Pequenas histórias, à moda do rapsodo ou de recortes da seção policial dos jornais, são inseridas ao longo da narrativa. Esse é o modo de organização da vida no conjunto habitacional. Não há uma única trajetória. Algumas destas histórias são horrendas, como a do marido que se acredita traído e esquarteja a criança, possível fruto do adultério. Assim sendo, justificase a ausência de heróis no romance. Não há espaço no mundo desfigurado para que heróis se sobressaiam, tampouco para que a forma estética esteja dedicada a representar um indivíduo.

Partindo desta organização do mundo da favela, a linguagem passa a ser um impasse, já que precisa dar conta da voz romanesca que emerge da forma, marcada pelo narrador, e da voz negra potente que ecoa das personagens moradoras do conjunto habitacional. O narrador em terceira pessoa apresenta-se com uma extrema preocupação na escolha lexical e com uma acentuada nota lírica. A oposição aparece quando concede a palavra às personagens, por meio do discurso direto e do indireto livre. Neste momento, o registro linguístico característico da população da Cidade de Deus se vê preservado. Palavrões, gírias, desvios sintáticos e prosódicos estão lá como constitutivos de um determinado modo de vida. O trecho abaixo serve como ilustração: 
Segunda-feira à noite, Inferninho foi tomar um passe no terreiro do Osvaldo:

- Tá com medo de morrer, esse menino?! Tá com medo de virar Exu?!? gargalhava. - Quanto tempo que você não vem falar comigo? - gargalhava. Eu não cobro a mais do que trato. Dou proteção aos moços e os moços não ligam pra mim. Quando a coisa melhora os moços esquecem do que eu peço. Mas fui eu quem foi lá no teu sonho - gargalhava. - O butina preta tá com vontade de fazer tua passagem, mas não ligue não, que ele tá amarrado no meu pé! - disse a pombagira.

Em seguida, pediu ao cambone que escrevesse o nome de Cabeça de Nós Todo num pedaço de papel, atravessou o papel com um punhal e colocou-o dentro de um copo com cachaça. Deu baforadas de charuto no copo, gargalhou e continuou:

- Tu vai ter que enterrar isso aqui em Calunga Grande na segunda-feira e deixa o resto comigo. Depois de vinte tempo o butina preta vai se foder na sete encruzilhada que passar. Depois você volta aqui pra falar comigo. Agora você bebe um pouco disso aqui e pede em pensamento o que você quer. (LINS, 2002, p. 133-134)

Se Paulo Lins não é praticante da tradição de matriz africana, entende minimamente os procedimentos de um terreiro. O trecho capta com grande aproximação o diálogo entre as divindades e os seres terrenos. As várias gargalhadas inseridas ao longo da fala são exemplo disto. A personagem Inferninho, após um sonho que a desestabilizou, buscou o auxílio na religiosidade para receber conselhos sobre o que fazer. Este contexto faz parte do imaginário suburbano do Rio de Janeiro, lugar onde nasceu a umbanda, religião de matriz africana, que mistura elementos do catolicismo e do espiritismo.

Paulo Lins percebe a complexidade da linguagem que constrói e a expressa textualmente dentro da obra:

Poesia, minha tia, ilumine as certezas dos homens e os tons de minhas palavras. É que arrisco a prosa mesmo com balas atravessando os fonemas. É o verbo, aquele que é maior que o seu tamanho, que diz, faz e acontece. Aqui ele cambaleia baleado. Dito por bocas sem dentes nos conchavos dos becos, nas decisões de morte. A areia move-se no fundo dos mares. A ausência de sol escurece mesmo as matas. O líquido-morango do sorvete mela as mãos. A palavra nasce no pensamento, desprende-se dos lábios adquirindo alma nos ouvidos, e às vezes essa magia sonora não salta à boca porque é engolida a seco. Massacrada no estômago com arroz e feijão a quase-palavra é defecada ao invés de falada.

Falha a fala. Fala a bala. (LINS, 2002, p. 21) 
Esse é um trecho que aparentemente está disperso no livro. Observando-o atentamente, vê-se que organiza a questão da linguagem na obra. Lins enuncia o esmagamento da linguagem do texto em prosa pela matéria violenta. Também é possível interpretá-lo como uma síntese das várias histórias que o grupo de pesquisa ouviu ao longo do trabalho de campo. Todas elas certamente constroem-se como narrativas de violência, marcadas pelo barulho dos tiros.

O trecho torna-se significativo também porque representa um ponto de inflexão na narrativa. Colocado logo no início do romance, antes dele há uma ambientação silenciosa do complexo habitacional. O protagonismo é da personagem Busca-Pé, que se sente desamparado e insatisfeito com sua condição periférica. Queria ser fotógrafo. A partir da chegada dos novos moradores, vindos de diferentes comunidades do Rio de Janeiro, passam a surgir as primeiras rixas. Então a bala começa a falar. A narração abandona a ambientação e o leitor é arremessado diretamente para o assalto ao caminhão de gás. O trecho recuperado anuncia o conjunto de acontecimentos que começarão a se desenrolar no romance.

Já repetimos mais de uma vez que Cidade de Deus traça um panorama da violência contra os negros e pobres no Rio de Janeiro. No entanto, há momentos em que a violência fica em segundo plano. Os professores Eduardo de Assis Duarte e Adélcio de Sousa Cruz (2011) chamam esses momentos de "ilhas de alívio temporal para o leitor" (DUARTE (Org.), 2011, p. 268). Tais momentos são preenchidos, segundo eles, por elementos da cultura negra urbana, como o carnaval e a religião afro-brasileira. $\mathrm{O}$ trecho já citado de Inferninho indo até um terreiro é um destes momentos. Acrescentamos ainda mais um recurso que serve como ilha de alívio temporal: há passagens em que Paulo Lins suspende o ritmo aligeirado e o preenche com um alargamento temporal: 


\begin{abstract}
Martelo não pensava em encontrar a polícia àquela hora, imaginava ser o momento da troca de serviço tanto dos policiais militares como dos civis. A manhã tinha crianças brincando nas vielas, outras indo para as escolas, pessoas rumando para o trabalho. Observou um menino andando à sua frente. Seu filho seria bonito igual a ele, mas não o deixaria de pé no chão, sem camisa e de short rasgado. Traria balas para o filho todos os dias. A brisa fresca da manhã alisava-Ihe o rosto, dava corda a seus pensamentos. O olhar acompanhava as pontas dos sapatos a cada passo que seus pés faziam [...] Tudo que the ocorria era bom, parecia convergir para um final feliz. (LINS, 2002, p. 126-127)
\end{abstract}

No fragmento acima, o criminoso Martelo, após um assalto, decide deixar a vida do crime. Sai então caminhando pela rua e há uma suspensão na cena de perseguição que se desenrola. Próximo a ele está o policial Cabeça de Nós Todo, buscando obstinadamente matar um dos bicho-solto. Entretanto, o leitor é retirado da cena e colocado em outro plano. Paulo Lins cria uma subjetividade interessante para alguém que fora retratado objetivamente, como um indivíduo que comete crimes em busca de dinheiro, até então. A ilha de alívio temporal tem a função de prender a atenção de quem lê por um outro viés, o da surpresa. Não se sabe, inicialmente, como terminará uma passagem com tamanho lirismo.

Acerca do lirismo na obra, Roberto Schwarz reflete:

\begin{abstract}
A importância deliberada e insolente da nota lírica, que faz frente ao peso esmagador dos condicionamentos pela miséria, dá ao romance um traço distintivo, de recusa, difícil de imaginar num escritor menos inconformado. Seria interessante refletir sobre a ligação entre esse lirismo improvável e a força necessária ao deslocamento do ponto de vista de classe - de objeto de ciência a sujeito da ação - que observamos a propósito do papel da enquete social na obra. (SCHWARZ, 1999, p. 170)
\end{abstract}

A relação que o crítico incita parece-nos levar ao caminho de atribuir-se à nota lírica a capacidade de transformar o objeto de ciência em sujeito de ação estética. Paulo Lins converte dados em lirismo não só por uma necessidade estética, mas também por 
uma vontade negra de tomar a palavra. A narrativa romanesca em Cidade de Deus tem um traço fundamental, que é a dicção negro-periférica construída através de modelos não usuais para ela. De alguma forma, Lins confere à palavra negra, quase sempre silenciada, o direito à forma estética, o que significa um salto significativo no modo de representação da violência e da exclusão racista na literatura contemporânea brasileira.

A formação brasileira baseada na democracia racial cria uma problemática para a forma estética negra. Como é possível que narrativas negras se constituam de maneira afirmativa e representativa já que a literatura tout court (DUARTE, 2008) tem seus modos de narrar consagrados. Pesa sobre Paulo Lins o fato de seu romance ter um direcionamento evidente e reafirmado pelo autor em entrevista (LINS, 2017), que não é para os próprios moradores da favela. Neste sentido, lemos sua obra como um ímpeto de validação no campo literário, preservando a matéria negra. A violência é a espinha dorsal de Cidade de Deus. Todavia, sua construção propõe criar um painel muito mais amplo sobre como a população negra é violentada todos os dias e que, por consequência, acaba também se tornando ator desta violência.

Tomemos como exemplo a justificativa de vários bicho-solto para manter-se na vida do crime: não se tornar um "otário", mandado por um patrão. A presença do trabalhador na obra contrapõe a existência dos bicho-solto e explicita o papel crucial da desigualdade social e do racismo como norteadores das relações sociais. O racismo estrutural está posto no romance, tanto na ação da polícia, quanto no ímpeto dos criminosos de combater o racismo por meio de ações violentas:

- Grande que matava policiais por achar a raça mais filha-da-puta de todas, essa raça que serve aos brancos, essa raça de pobre que defende o direito dos ricos. Tinha prazer em matar branco, porque branco tinha roubado seus antepassados da África para trabalhar de graça, o branco criou a favela e botou 
o negro para habitá-la, o branco criou a polícia para bater, prender e matar o negro. Tudo, tudo o que era bom era dos brancos. O presidente da República era branco, o médico era branco, os patrões eram brancos, o-vovô-viu-a-uva do livro de leitura da escola era branco, os patrões eram brancos, as bonecas eram brancas [...]. (LINS, 2002, p. 175-176)

O primeiro destaque deve ser a construção agônica que Paulo Lins estrutura a partir da uma enumeração incessante. Mais de uma vez o autor utiliza de forma assertiva este recurso. O recurso estético contribui para que o excerto se converta em uma síntese do quadro racista da sociedade brasileira, visto da favela. Ao elencar todas as entidades brancas ao seu redor, a personagem negra problematiza uma série de instituições sociais que são racistas por excelência e não se reconhecem como tal. A violência policial está desnuda, mostrando como a polícia pode ser capaz de atender apenas a uma determinada classe e mais do que isso, desvela a falta de consciência de classe uma vez que muitos dos policiais advêm das classes subalternas, a qual atacam e matam todos os dias.

Vale ainda destacar na citação acima o modo como os policiais, "raça que serve aos brancos". Cabeça de Nós Todo é um policial de origem nordestina, que, várias vezes, destila sua raiva contra os bicho-solto, chamando-os de "crioulos". Seria possível lembrar o pedreiro nordestino que mata o peixeiro negro, destila seu preconceito e vai embora para o nordeste. Esse indício nos ajuda a perceber o quanto o racismo é estrutural, na medida em que a dimensão racial é mais forte do que a identidade de classe. Ele está fora de Cidade de Deus (no Presidente, etc.), mas também atravessa as relações sociais dentro do conjunto.

Roberto Schwarz caracterizou o princípio organizador da obra. No caso, ele se concentra em como Paulo Lins levou para a forma do romance a fratura social. Seu olhar se concentra na ordem/desordem social brasileira, calcada na desigualdade social e na 
exclusão espacial e social, dos pobres e dos trabalhadores. A novidade de Cidade de Deus, não apenas em relação ao naturalismo, está neste ponto de vista interno. No presente artigo, a intenção foi a de avançar a leitura feita por Schwarz, ao mostrar o quanto a matéria negra atravessa e constitui a forma do romance de Paulo Lins. Nossa hipótese é que, ao trazer a dicção negro-periférica para a análise, a configuração do princípio narrativo ganha mais precisão. Do mesmo modo, ao trazer Paulo Lins para o sistema literário, tal como pensado por Antonio Candido, conseguimos perceber omissões, recalques e lacunas da sua formulação. Assim, Cidade de Deus não abre apenas uma nova tendência literária, mas ajuda a delinear um fio que desvela o caráter excludente de um sistema literário branco. Num país que ainda convive com as marcas da escravidão, não se pode recalcar esse fio da literatura negra.

A leitura de Cidade de Deus que tentamos engendrar até aqui coloca o romance como um marco em narrativas de violência que, mais adiante, desaguaram na literatura marginal-periférica e em outras obras que constituem esta perspectiva. Desta forma, Paulo Lins inscreve-se no sistema literário pela proposta arrojada que tenta levar a cabo com Cidade de Deus. A aventura estética proposta pelo escritor faz triunfar a matéria negra sobre a batalha das formas estéticas consagradas.

\section{Referências}

ADORNO, Theodor W; HORKHEIMER, Max. Dialética do Esclarecimento: fragmentos filosóficos. Tradução de Guido Antônio de Almeida. Rio de Janeiro: Zahar, 2006 (1985).

ALMEIDA, Silvio. O que é racismo estrutural? Belo Horizonte: Letramento, 2018.

CANDIDO, Antonio. Formação da literatura brasileira: momentos decisivos 1750 - 1880 . Rio de Janeiro: Ouro sobre azul, 2013.

COSTA, Keila Prado. "O que é meu é meu, o que é seu é nosso: questões de/sobre Cidade de Deus". In: Criação \& Crítica. São Paulo: FFLCH - USP, n. 1, 2008, p. 31-43. Disponível 
em: http://www.revistas.usp.br/criacaoecritica/article/view/46753. Acesso em 22 set. 2019.

CUTI (Luiz Silva). Literatura Negro-Brasileira. São Paulo: Selo Negro, 2010.

DALCASTAGNÈ, Regina. "A auto-representação de grupos marginalizados: tensões e estratégias na literatura contemporânea". In: Letras de Hoje. Porto Alegre: PUCRS, v. 42, n. 4, 2007, p. 18-31. Disponível em:

http://revistaseletronicas.pucrs.br/fo/ojs/index.php/fale/issue/view/303. Acesso em 15 set. 2019.

DUARTE, Eduardo de A. (Org.). Literatura e Afrodescendência no Brasil: antologia crítica. Vol. 3. Belo Horizonte: UFMG, 2011.

. "Literatura afro-brasileira: um conceito em construção". In: Estudos de Literatura Brasileira Contemporânea. Brasília: UnB, n. 31, 2008, p. 11-23. Disponível em: http://periodicos.unb.br/index.php/estudos/article/view/2017. Acesso em 14. set. 2019. LINS, Paulo. Cidade de Deus. São Paulo: Companhia das Letras, 2002.

. Paulo Lins: 20 anos de Cidade de Deus. Entrevista concedida ao Itaú Cultural. São Paulo, 2017. Disponível em: https://www.youtube.com/watch?v=ZS8IdK8Ekal. Acesso em 13 jan. 2019.

SCHWARZ, Roberto. "Cidade de Deus". In: SCHWARZ, Roberto. Sequências brasileiras: ensaios. São Paulo: Companhia das Letras, 1999. p. 163-171.

Recebido em 23 de maio de 2019.

Aceito em 05 de dezembro de 2019.

\footnotetext{
${ }^{1} \mathrm{O}$ presente artigo faz parte do projeto de pesquisa, recém-concluído, “A prosa interrompida: o problema da categoria do Realismo em Machado". A pesquisa segue em andamento, agora dentro do projeto "Realismo, alegoria, gênero e escravidão: um estudo do conto machadiano", ambos desenvolvidos com o apoio do CNPq, sob orientação do Prof. ${ }^{\circ}$ Dr. Antônio Marcos Vieira Sanseverino. Dentro do escopo da investigação constrói-se um aparato conceitual comum, que estrutura as análises literárias, cujo ponto comum é a categoria do Realismo, o que permite leituras das obras de Machado de Assis e de autores contemporâneos, como é o caso de Paulo Lins.

2 Roberto Schwarz publica seu ensaio logo depois da publicação da primeira versão da obra, em 1997. Em 2002, após o lançamento da adaptação, uma segunda edição do romance é publicada, revista pelo autor. Lins promove significativas mudanças, fazendo inúmeros cortes e mudando os nomes dos personagens, com o objetivo de evitar processos judiciais e, segundo ele, para dar autonomia ao livro em relação ao filme de Fernando Meirelles e Kátia Lund. Neste artigo utilizamos a versão de 2002.
} 